\title{
El Espejismo Liberal La Economía Política del Uruguay en los Inicios del Siglo XXI (2000-2005)
}

\section{Gustavo Arce*}

Resumen: Este artículo analiza las principales medidas, tanto económicas como políticas y sociales, adoptadas por el gobierno del Presidente Batlle durante el período del 2000 al 2005. Para ello se relaciona la apertura económica, el proceso de endeudamiento y la explosión de la pobreza.

Palabras-clave: Economía Política, Endeudamiento, Crisis Financiera, Derechos Humanos, Pobreza.

Abstract: This article presents and analyzes some of the most relevant economic and politic events produced in Uruguay during the 2000-2005 period. It examines the principal trends of the national economy's structure, emphasizing the relations among the global economy, the growth of the debt and the growth of poverty.

Keywords: Political Economy, Uruguay, Debts, Financial Crises, Poverty.

* Profesor Titular de Economía Política y de Economía I y II y Coordinador de la Licenciatura en Relaciones Internacionales. Facultad de Derecho. UdelaR. E-mail: arpu@adinet.com.uy. Recebido em 10/04/07 e aceito em 31/10/07. 


\section{Introducción}

Este texto resume parcialmente las intervenciones que el autor realizó en:

- los cursos y seminarios que sobre el MERCOSUR y sus relaciones con otros bloques geo-económicos que funcionan en el espacio económico mundial, dictó como profesor invitado en el mes de enero del 2005, en el Departamento de Economía y Gestión, en la Universidad de París 8, en Francia, con la cual la UdelaR mantiene relaciones institucionales fruto de un Convenio de Cooperación Internacional.

- el Seminario-Taller "20 años de investigación en los temas del Área SocioJurídica” de la Facultad de Derecho, lo cual exigió revisar analíticamente la literatura económica nacional acerca de cómo fue abordada por la misma, las cuestiones relativas a la producción del Saber, la propiedad intelectual y sobre los llamados bienes públicos.

En la presente versión el análisis se centra en tres puntos. En primer lugar se analiza la relación entre la apertura comercial, el endeudamiento interno y externo, y, el aumento de la pobreza; después, se ve rápidamente el Uruguay en su región y ésta en la economía mundial; finalmente, se describen los hechos más relevantes de la administración Batlle.

Este trabajo es una versión resumida de la Primera parte de un libro: "El Uruguay en el Primer Lustro del Siglo XXI", elaborado en colaboración con Daniela Guerra, producido en la Cátedra de Economía Política y de Economía I y II de la Facultad de Derecho de la UdelaR, quien auspició dicha publicación y que está actualmente en proceso de edición por la Fundación de Cultura Universitaria.

\section{Apertura comercial, endeudamiento y pobreza 2000-2005}

Fruto de la reforma constitucional aprobada en el mes de noviembre de 1996 el abogado - Dr. Jorge Batlle Ibáñez - venció en las elecciones nacionales de 1999 y en la segunda vuelta al médico - Dr. Tabaré Vázquez -. Un acuerdo político entre los Partidos Colorado y Nacional, acaecido entre las dos vueltas, hizo que el Dr. Batlle obtuviera 1.158 .708 votos emitidos $(59,1 \%)$, mientras que el candidato del Encuentro Progresista-Frente 
Amplio, alcanzó la cifra de 981.778 sufragios (45,9\%).

El triunfo electoral de 1999 le permitió al Dr. Jorge Batlle acceder a la Presidencia de la República el $1^{\circ}$ de marzo de 2000, con una legitimidad sin precedentes en la historia política nacional, pues se convirtió en el primer presidente a ser electo con la anuencia de más de la mitad del cuerpo electoral uruguayo.

Miembro de una de las más conspicuas familias ${ }^{1}$ del Partido Colorado, figura destacada y de prolongada presencia en el sistema político nacional, el novel Presidente constituyó un gobierno de coalición ${ }^{2}$ entre el Partido Colorado y el Partido Nacional.

En su discurso de asunción a la primera magistratura del Estado el $1^{\circ} \mathrm{de}$ marzo de 2000, frente a los miembros de la Asamblea General, el Presidente, luego de los saludos protocolares, afirmó, en primer lugar, su adhesión a los principios liberales, según los cuales, el buen desempeño económico de los pueblos y de las Naciones, sólo es posible en mercados libres y competitivos, tanto a escala internacional como nacional:

(...) Los tiempos del mercantilismo proteccionista comenzaron a caer y quedar atrás a partir de 1820, y las transferencias tecnológicas de entonces, la baja abrupta en los precios y en los fletes de los transportes, las inmigraciones masivas, los flujos de capital, que por entonces y en términos desestacionados eran mayores en aquella época que los que aún son hoy, las inmigraciones -como decía - permitieron asistir, en la segunda mitad del siglo XIX y en los primeros veinte ańos del Siglo XX, a un mundo abierto, en el cual aun las naciones más débiles que recién nacían a la vida institucional pudieron crecer y pudieron desarrollarse. Al influjo de pueblos decididos y de gobiernos ilustres, los países de nuestra

\footnotetext{
${ }^{1}$ Hijo del ex Presidente, Luis Batlle Berres (1947-1951); sobrino nieto del también ex Presidente, José Batlle y Ordoñez (1903-1907 y 1911-1915) y bisnieto del General Lorenzo Batlle, Presidente entre 1868 y 1872.

${ }^{2}$ El acuerdo implicó, fundamentalmente, la coparticipación del Partido Nacional en el Gabinete del Poder Ejecutivo. De los 13 Ministerios, el Partido Nacional ocupó 5: Ministerio de Trabajo y Seguridad Social (Cr. Álvaro Alonso); el de Industria, Energía y Minería (Dr. Sergio Abreu); el de Educación y Cultura (Dr. Antonio Mercader); el de Vivienda, Ordenamiento Territorial y Medio Ambiente (Ing. Carlos Cat) y el de Deportes (Sr. Jaime Trobo). Este Ministerio fue creado ese mismo año, como consecuencia de las negociaciones políticas que dieron nacimiento a la coalición gubernamental, presidida por el Dr. Batlle. El Ministerio de Ganadería, Agricultura y Pesca fue confiado al Ing. Gonzalo González de filiación blanca, pero quien accedió al cargo como técnico.
} 
América alcanzaron niveles de justicia, de equidad y de desarrollo, que los colocaron, por cierto, en muchos casos, a la vanguardia del crecimiento. El Uruguay sin duda fue uno de ellos (...)

(...) Las regulaciones, los monopolios, los oligopolios, las trabas en todas sus formas, los mercados protegidos, tanto a los sectores públicos como a los privados, dificultan y entorpecen la evolución de esta sociedad uruguaya. Este tema será inexorablemente el asunto central de los próximos años. Y este país y este Parlamento y el gobierno lo debe considerar, sin temor, en un diálogo en donde la realidad ocupe la cabecera de la mesa y presida nuestro análisis (...) (DISCURSO PRESIDENCIAL, 2000).

Luego, el Presidente mencionó el largo y conflictivo período en que la Economía Mundial y las relaciones internacionales se organizaron y estructuraron en el orden bipolar y, como consecuencia de la autodisolución de la URSS (1989-1991) es: “(...) recién en los últimos 10 años que el mundo se ha lanzado a un nuevo ciclo de apertura y globalización, proceso sostenido y alentado por los formidables cambios científicos y tecnológicos de los que hoy somos testigos (...)" (DISCURSO PRESIDENCIAL, 2000).

A continuación el Dr. Batlle, aclaró que fue el Uruguay de la postdictadura el que optó integrarse decididamente al mundo global y dinámico; rindió tributo a los gobiernos que le precedieron, y reivindicó una cierta continuidad programática e ideológica, de su futura gestión, con aquellos que habían conducido el país desde 1985 hasta la fecha:

(...) En el Uruguay, recién a partir de 1985 y en las administraciones sucesivas del Dr. Sanguinetti, primero, del Dr. Lacalle después, del Doctor Sanguinetti finalmente, comenzamos a tomar conciencia de la necesidad de incorporarnos a esta nueva realidad.

Han sido 15 años de procesos difíciles, iniciados con la apertura cambiaria en la década del 70 y alcanzados, finalmente, en esta administración a través de la reforma de la Seguridad Social, el comienzo de la reforma del Estado y el consenso de que el país sólo crece sin inflación, sin déficit 
fiscal y con estabilidad cambiaria sin duda definitivamente arraigado entre nosotros.

Hoy al admitir que un tiempo ha concluido y que son importantes los logros y cambios positivos que la sociedad uruguaya ha alcanzado, reconocemos implícitamente que otro es el período que comienza.

Por cierto que tiene importantes diferencias con aquél tanto hacia el exterior como hacia lo interno. Actualmente no contamos como entonces con un mercado europeo abierto a nuestros productos primarios, que es notorio que América los produce en igualdad calidad y mejor precio que cualquier otro productor. Pero tampoco es similar hacia adentro, puesto que es un contraditio in se no advertir que para integrarse a un mundo globalizado, no se puede estar, al mismo tiempo, abierto hacia afuera y cerrado hacia adentro (...) (DISCURSO PRESIDENCIAL, 2000).

Finalmente, el Presidente le anunció al Parlamento y a la ciudadanía toda, la impronta gubernamental de su administración para el período 20002005. En primer lugar, indicó los temas relativos a las reformas de segunda generación que implicarían tanto al sector público como al privado, en segundo lugar, hizo mención al mejoramiento de los precios y de la calidad de los servicios ofertados por el sector público, en tercer lugar, el presidente sostuvo la necesidad de profundizar la descentralización administrativa del Estado, después se refirió a la necesaria desregulación de todas aquellas actividades del sector privado en la cuales la situaciones monopólicas inhiben la competencia capitalista. Para concluir el presidente se refirió a la necesaria profundización de la reforma de la seguridad social.

La intensificación de los mecanismos de la competencia capitalista en los mercados privados y públicos, la austeridad en el uso de recursos materiales y financieros de la hacienda pública, desencadenarían un proceso de crecimiento económico y de modernización social que permitirían:

(...) el bienestar de los ciudadanos, la justicia, la solidaridad, la igualdad de oportunidades y la libertad. Estas medidas entre otras son las que nos van a permitir atender nuestras obligaciones con la salud (a la cual 
el Uruguay le destina 10\% del Producto) y para cuyo ordenamiento tenemos el honor de haber podido pedirle, y que él haya aceptado, al ex decano de la Facultad de Medicina, el Dr. Eduardo Touya que sea nuestro Director Nacional de Salud. Asimismo nos permitirán ocuparnos de temas fundamentales como educación, seguridad, vivienda. Estas medidas le darán a los ciudadanos del Uruguay las condiciones de vida a la que tienen derecho por el sólo hecho de ser, de existir y de vivir en este país de libertad y de justicia (...) (DISCURSO PRESIDENCIAL, 2000).

Con el aumento de las condiciones por las cuales los mecanismos del mercado afectan racionalmente los recursos y los precios, el incremento de la riqueza (el P.B.I.), permitiría una mejor distribución de la misma, destinada fundamentalmente a mejorar las paupérrimas condiciones de vida de aquellos ciudadanos sumergidos en la informalidad económica y en el desamparo social y cultural. Es por ello que:

(...) solamente las sociedades de economías abiertas y de alta incorporación tecnológica tienen tasas de desempleo aceptables. El Uruguay y puede y debe transformarse en una nación de este porte (...).

(...) Hemos venido desarrollando hasta ahora y con éxito una muy fuerte política de apoyo a la educación en los sectores más débiles de la sociedad y además entre los niños antes de enfrentar la escuela. Hemos hecho muchísimo en esa materia. Lo continuaremos haciendo. Atenderemos, con los recursos ya obtenidos, los sectores instalados en los así llamados "asentamientos precarios", afirmamos que el Gobierno Central, ante el error de algunos municipios en el manejo territorial, está dispuesto a adquirir tierras; más que dispuesto, está decidido a adquirir tierras y a fraccionarlas en lotes con servicios, para evitar que los ciudadanos, en violación de los derechos de propiedad, muchas veces no tengan otro camino que ocupar un terreno para vivir, en un país donde sobra tierra y falta gente (...) (DISCURSO PRESIDENCIAL, 2000). 
También el Presidente pensaba en el futuro y, es por eso que su administración buscaría que la sociedad uruguaya ingrese en la economía de la información y en la Sociedad de la Información:

(...) La economía hoy, es la economía del "conocimiento", y por lo tanto en él se basa esencialmente la expectativa de crecimiento del Uruguay.

De igual modo que las grandes redes ferroviarias, las autopistas, los grandes puertos, las represas, constituyeron la piedra angular de la sociedad industrial, los sistemas de información son hoy la infraestructura básica del nuevo tiempo.

Todos nuestros jóvenes (y aún aquellos que no lo son tanto) tendrán que ser alfabetos electrónicos de la misma forma como antes aprendíamos los palotes, las primeras letras, a leer y escribir. En la actualidad, los países que están a la vanguardia en el mundo ya no son más aquellos con grandes riquezas naturales solamente. Los vientos que soplan en este momento han remplazado algunos paradigmas. Términos abstractos como "información", "conocimiento" hoy son pilares concretos de poder y las autopistas de la información (como la Internet) han cambiado no solamente las economías de los países sino la vida de los países

Es hora que el Estado pues, asuma en este caso su papel integrador, superando antagonismos anacrónicos. En el mundo que adviene, a la Universidad, a todo el sistema educativo, público y privado, a nuestra empresa de telecomunicaciones, les corresponde jugar un papel excepcional. El Estado será junto a la sociedad civil un gran factor de unión y de reencuentro, reincorporando así, en un mundo en el que las fronteras físicas tienden a desaparecer, a multitud de uruguayos que hoy residen fuera del país, para que compartan la gran causa del despegue de esta sociedad (...) (DISCURSO PRESIDENCIAL, 2000).

Para culminar de citar las proposiciones que el nuevo gobierno tuvo en materia de política nacional, el Dr. Jorge Batlle expresó su firme voluntad de sellar la paz entre los uruguayos”: “(...) Como lo hemos hecho hasta 
ahora, en los próximos cinco ańos, llegaremos a todos los sectores de nuestra nación para escuchar, para informar, para dialogar y sostener, con la firmeza y claridad con que lo hemos hecho siempre, nuestras ideas y puntos de vista, en procura de los entendimientos y los acuerdos que aseguren la armonía de los uruguayos y sellen, para siempre - y sellen para siempre - la paz entre los uruguayos. Esa es nuestra obligación. Si tantas cosas hemos pasado y tantas hemos sufrido y nadie de nosotros puede decir que alguien es culpable o que alguien es inocente, esto no es resultado de un mundo maniqueo, de malos contra buenos, sino que todos estamos dentro de la misma historia, es a todos nosotros que nos corresponde como responsabilidad primera sellar para siempre la paz entre los uruguayos (...) (DISCURSO PRESIDENCIAL, 2000).

El Presidente hacía referencia al hecho de que su gobierno estaba decidido a culminar el largo y penoso proceso, iniciado al restaurarse el sistema democrático republicano ${ }^{3}$ de reparar a aquellos ciudadanos cuyos derechos humanos habían sido violentados como consecuencia de la "guerra interna" y de la instauración del gobierno dictatorial cívico-militar (1973-1985) encabezado por el Sr. Juan María Bordaberry.

Finalmente en materia de política internacional el gobierno en el poder desde el primero de marzo de 2000, creía profundamente en su región y su bloque - el Mercosur -, pero ambicionaba ampliarlo (con nuevos Estados miembros y/o con nuevos temas: la sociedad del conocimiento) y hacerlo compatible con la gran iniciativa que el Presidente norteamericano, en ejercicio entre 1988 y 1992, George Bush había lanzado en 1990: una gran zona de libre comercio desde Alaska a Tierra del Fuego:

\footnotetext{
${ }^{3}$ Durante el primer gobierno del Dr. Julio María Sanguinetti (1985-1999) se aprobaron leyes de Amnistía para forjar la "reconciliación nacional". El 8 de marzo de 1985 entró en vigencia la Ley 15.737 por la cual se decreta la amnistía para todos los delitos políticos, comunes y militares conexos con éstos, cometidos a partir del primero de enero de 1962; se creó, también, la Comisión Nacional de Repatriación, para facilitar el regreso de nacionales exiliados. El 22 de diciembre de 1986, lo hizo la Ley 15.848, por la cual se reconoce que ha caducado el ejercicio de la pretensión punitiva del Estado respecto de los delitos cometidos hasta el primero de marzo de 1985, por funcionarios militares y policiales, equiparados y asimilados por móviles políticos o en ocasión del cumplimiento de sus funciones y ordenados por los mandos que actuaron durante el período de facto. Esta ley fue objeto de un Referéndum en 1989, por el cual, el cuerpo electoral respaldó dicha ley.
} 
El Uruguay, país abierto y de vocación internacional, respetuoso de las leyes y de las libertades, no podía menos que integrar, desde el primer día, como su Constitución lo establece, el Tratado de Asunción. Hemos crecido en el Mercosur y no nos molestan las crisis, porque ellas sirven para corregir los errores. Hemos avanzado en pocos años más que otras naciones en muchos. Nuestro objetivo en el Mercosur, como uruguayos, es ampliarlo, es consolidarlo. Sentimos al Mercosur, integrado y abierto al mundo, ordenado en su funcionamiento por una Secretaría Técnica, confirmado en sus instituciones por soluciones arbitrales, en la búsqueda permanente de ampliar la región con la incorporación de otras naciones de América, para que en algún momento éstas, que tienen por su origen histórico una vocación de unidad heredada de nuestros grandes libertadores, conformen un mercado formidable desde Alaska hasta Ushuaia...

En la educación superior también vamos a poner énfasis. Estamos convencidos que desde la Universidad de la República, con su Rector el Ing. Guarga y con los actores de la actividad privada, vamos a poder hacer una enorme cantidad de cosas dentro y fuera del país. Y además el Mercosur no es solamente un Mercosur político - como lo es - ni tampoco solamente un Mercosur económico -como también lo es - y es importante que lo siga siendo y se perfeccione. También tiene que ser un Mercosur cultural, un Mercosur científico, un Mercosur tecnológico en donde el conocimiento de nuestra academia de gente intelectualmente superior de estas naciones se junte para poder hacer cosas en común y desarrollar una civilización no solamente como nos corresponde sino como estamos obligados a hacerla en esta América que es grande por lo que ha hecho y por lo que puede hacer entre todos juntos (...) (DISCURSO PRESIDENCIAL, 2000).

Durante todo el transcurso de esa jornada de transmisión de mando presidencial se percibió tanto en el ánimo de la ciudadanía como en el de los miembros del sistema político nacional, un cierto "espíritu” republicano; el Dr. Batlle simbolizó en una frase que su gobierno no sólo afianzaría las instituciones republicanas, sino que la austeridad guiaría el manejo de los fondos públicos ("sólo café y agua mineral en los ágapes protocolares") y, al 
final de su primer jornada como Presidente de la República, el Dr. Batlle, decidió culminarla retirándose en un taxímetro, uno de los tantos que habían sido utilizados en su campaña publicitaria electoral, en la cual como un ciudadano "de a pie", el entonces candidato Batlle, le "cantaba la justa" a los uruguayos.

Cinco ańos más tarde, el Dr. Batlle cedería la banda Presidencial al Dr. Tabaré Vázquez - el líder del Encuentro Progresista-Frente Amplio-Nueva Mayoría - que había logrado 50,45\% de votos en la primera vuelta de las elecciones nacionales del 31 de octubre de 2004, superando al candidato del Partido Nacional, Dr. Jorge Larrañaga, que obtuvo 34,30\%, al del Partido Colorado, Esc. Guillermo Stirling, que alcanzó $10.36 \%$ y al Partido Independiente con su candidato Dr. Pablo Mieres que lograron alcanzar el número de 41.011 sufragios $^{4}$.

Al finalizar su mandato, la administración conducida por el presidente Batlle, dejó no solamente un casi - electoralmente - inexistente Partido Colorado (10 diputados en 99 y 3 senadores en 31) sino también un Uruguay, social y económicamente empobrecido, como si un maremoto $\mathrm{u}$ otra catástrofe natural hubiera sumergido a su población en la desolación, el estupor y la impotencia.

En el lapso de los años de 2000 a 2004, la economía nacional logró aumentar su grado de apertura en las relaciones económicas internacionales, pues la parte de su comercio exterior sobre el PBI pasó del 28,8 al 44,8\%, pero en cambio, el valor de su producción de bienes de uso final descendió de 20.075 millones de dólares a 13.216 (una variación de un $34 \%$ menos). El saldo de la balanza comercial fue negativo, excepto en 2003, la formación bruta de capital fijo sobre el PBI siguió siendo, como sucede desde varias décadas, extremadamente baja (alrededor de un 11\%, en promedio, para el período); la inversión directa extranjera apenas alcanzó un 2\% (en promedio) sobre el PBI, a pesar de una legislación muy favorable vigente desde 1974.

En el transcurso del primer semestre de 2005 se conoce públicamente: primero, el informe "Estimaciones de pobreza por el método del Ingreso" del Instituto Nacional de Estadísticas (INE) ${ }^{5}$, después, "Desarrollo Humano en

\footnotetext{
${ }^{4}$ Además de los guarismos mencionados se escrutaron: 31.031 votos en blanco (1,39\%), 21.541 anulados (0,97\%) y 5.492 (0,69\%) en el rubro "otros" (EL OBSERVADOR 2004-2005, p. 24).

${ }^{5}$ A consultar en Amarante e Vigorito (2006).
} 
Uruguay 2005", el informe del Programa de las Naciones Unidas para el Desarrollo (PNUD).

El informe del INE estima la pobreza según el ingreso de los hogares con respecto a umbrales o líneas que representan:

- el costo de una canasta de alimentos considerados básicos para la correcta nutrición de una persona en un mes (línea de indigencia).

- el costo en alimentación y otros bienes y servicios no alimenticios en función de la cantidad de miembros del hogar y de la presencia, o no, de niños o adolescentes (línea de pobreza).

En los 4 años analizados, el número de indigentes urbanos y el de indigentes se duplicó (de 2 a 4\% en el primer caso, y de 16 a 27\% en el segundo caso).

El segundo informe, en su primera parte consagrada al tema "Desarrollo Humano y Pobreza en Uruguay" es lapidario y contundente pues demuestra claramente la evolución reciente de la pobreza en el Uruguay, sobre todo en el período analizado en este trabajo, pues: “(...) el deterioro del ingreso de los hogares provocados por la crisis económica determinó un fuerte incremento de la pobreza medida a través de ambos umbrales que afectó en el 2003 al $41 \%$ de la población urbana (...)” (PROGRAMA DE LAS NACIONES UNIDAS, 2005, p. 99).

En cuanto a la reforma del Estado, a la transformación del sector público y a la voluntad esgrimida al asumir su mandato, de "reordenar y disminuir el gasto muchas veces innecesario y redundante", un primer balance muestra que las cuentas públicas arrojaron un saldo negativo y que la deuda pública pasó de un 40,8 \% del PBI en el año 2000 a un 100,9 \% en el 2004.

La austeridad en el manejo de los recursos estatales no se hizo presente en el gobierno del Dr. Batlle. Una ciudadanía atónita por el aumento del endeudamiento y de la pobreza, lee en la prensa un informe de la Auditoría Interna de la Nación, publicada en el Diario Oficial en el que las irregularidades, las omisiones y los abusos en y con los bienes estatales se acumulaban en un contexto socio-económico dominado por la exclusión social de vastos sectores de la población uruguaya. Recordemos sólo algunos ejemplos: 
"Evasión. Mientras que paga publicidad para promover el pago de impuestos y combatir la evasión, la Presidencia de la República evade al Banco de Previsión Social (BPS). Por eso la AIN le recomienda abonarle al BPS los aportes por la partida de alimentación que cobran los funcionarios presupuestados y contratados, que en muchos casos supera el 20\% del líquido del sueldo y constituye un ingreso regular y permanente.

Ganadería, el Caos. En Ganadería los auditores de la AIN se hicieron un festín con el lápiz rojo. Encontraron comprobantes pendientes de rendición por la suma de $\$ 4.546 .369$ cuya antigüedad data de los años 1998, 1999 y 2000. También faltaba rendir gasto de $\$ 78.860$. Había garantías de licitaciones que en su mayoría estaban vencidas y no formaban parte del saldo de caja. "Se constató que se le abonaron a un funcionario dos viáticos un mismo día por diferentes destinos”, dijo la AIN, y añadió que el ministerio no cuenta con un inventario de bienes muebles, útiles e instalaciones. El 28 de setiembre de 2002 "se efectuó un importante remate de vehículos tendiente a reducir la flota automotriz" pero hoy hay allí más autos que en aquella fecha.

La AIN comprobó que nadie tiene un horario fijo de trabajo "Este régimen flexible es en sí mismo ilegítimo", dice la AIN, ya que "no permite controlar las llegadas tardes de los funcionarios. Lo señalado impide efectuar los descuentos salariales correspondientes y aplicar las sanciones disciplinarias procedentes cuando las llegadas tarde son reiteradas y configuran falta administrativa", añade. "El 28\% de los funcionarios del ministerio no registra asistencia"

Estas son algunas de las presuntas irregularidades, que podrían haber acaecido en los últimos diez ańos, y que fueron denunciadas ante la justicia por el presidente de la Empresa Pública Obras Sanitarias del Estado, el Ing, Carlos Colaccé.

En marzo de 2000, el primer gobierno del "ballotage" prometió crecimiento económico genuino y sostenido, fuerte presencia del Uruguay

${ }^{6}$ Idem nota 8 
en las relaciones económicas internacionales, una auténtica modernización capitalista mediante - según la ortodoxia liberal/neo-liberal/monetarista - una economía abierta a la competencia - interna y externa - a la par de instrumentar modificaciones en las regulaciones estatales. En marzo de 2005, la economía está más abierta al mundo, pero el crecimiento económico y la prosperidad faltaron a la cita, así como la proclamada reforma de "segunda generación" del Estado y del servicio público.

En cambio, el endeudamiento creció: el del sector público superó el valor del P.B.I., y el del interno llegó y llega representar un quinto del mismo P.B.I. La creciente informalidad económica y laboral, la emigración y una particular forma de administrar los recursos públicos caracterizaron à la administración gubernativa de este período.

Pero y además del descalabro económico/financiero de la administración Batlle, en la sociedad uruguaya se vienen procesando y manifestando cambios en el modo y forma de vivir, que provienen desde mucho antes del período histórico analizado en el presente trabajo. Los mismos pueden haber cobrado un nuevo impulso y desarrollo visto el contexto de crisis socioeconómico que imperó en esta administración. En el Uruguay del primer lustro del Siglo XXI, se producen dos suicidios por $\mathrm{día}^{7}$, la violencia doméstica y social ${ }^{8}$ se propaga y abarca, con desigual intensidad, a todas las capas sociales del país; la familia, base de nuestra sociedad ${ }^{9}$ ya se organiza (y se reproduce) de

\footnotetext{
${ }^{7}$ En el Uruguay, este es un tema en que las ciencias sociales en general no han, todavía, aportado explicaciones sobre las causas del fenómeno. El año record fue el 2002, cuando la tasa de suicidio alcanzó el guarismo de 17,8 por cada 100 mil habitantes. Los métodos más utilizados son las armas de fuego (44\%) y el ahorcamiento (40\%), según el Departamento de Medicina Legal de la UdelaR. Según el Ministerio de Salud Pública, en el año 2004, en el departamento de Florida se dio el pico máximo de suicidios (30,5\%), en Montevideo un 11\% y en Paysandú 10,9\%. Véase el diario El País (2006b, p. 16).

${ }^{8}$ El fenómeno más visible, aunque no todos los casos sean denunciados, es el de la violencia doméstica, en promedio cada nueve días, una mujer muere por esa causa. Expresión también de un fenómeno creciente de violencia y de inseguridad: el 51\% de la población uruguaya toma alguna medida para protegerse de la delincuencia. Desde las rejas hasta la posesión de armas de fuego. En Montevideo, 6 de cada 10 familias tienen algún mecanismo de protección; en el resto del país esa proporción es mucho menor. A medida que aumenta el nivel socioeconómico de una familia, también aumenta el consumo de seguridad (el 70\% de esos hogares poseen mecanismos de defensa; el en los déciles más pobres más de 60\% viven "sin protección”). Según encuesta y análisis realizados por Equipos Moris. En el diario El País (2005b, p. 14).

${ }^{9}$ Según el artículo 40 de la Constitución de la República: "La familia es la base de nuestra sociedad. El Estado velará por su estabilidad moral y material, para la mejor formación de los hijos dentro de la sociedad". El paradigma que implícitamente expresa el artículo 40 es el de la familia nuclear. El mismo se encuentra en plena mutación, aquí citamos algunos y diferentes ejemplos de ello: "La gente vive junta pero se casa menos. Desde 1985, por ejemplo, disminuyeron los matrimonios y se duplicaron los divorcios, las uniones sin papeles de por medio aumentaron un $70 \%$ y sólo un tercio
} 
manera diferente a la que los uruguayos estábamos habituados. Los hechos y fenómenos económicos analizados para el período 2000-2004, no están ajenos a lo que el Uruguay vivió en las últimas décadas ni a las mutaciones sociales que vienen conmoviendo a la economía mundial y al sistema internacional.

Es por ello que, aunque parcialmente, el próximo capítulo comienza con una breve presentación del Uruguay en la región, y de ésta en el mundo, y termina con una descripción de la evolución de sus principales recursos socio-económicos en el período analizado en este trabajo.

\section{El Uruguay y la Región: en los intersticios ${ }^{10}$ de la Economía Mundial}

En el primer lustro del Siglo XXI América Latina ocupa una posición relativamente periférica/intermedia, entre las regiones líderes y dominantes (América del Norte, Unión Europea y Asia) y las dominadas/excluidas de los frutos del crecimiento económico y del desarrollo social que conoce el Sistema Internacional y la Economía Mundial ${ }^{11}$. En efecto utilizando la feliz expresión de François Perraux (1987, p. 25), el "espacio económico del mundo", se encuentra tan notablemente polarizado como, peligrosamente jerarquizado y desequilibrado. Analizada por grandes regiones, la economía mundial muestra una primera dicotomía: Europa Occidental, América del

de los hogares está compuesto por una pareja y sus hijos. En el 2003, el 70\% de jóvenes con educación primaria y el 48\% con estudios terciarios que vivían en pareja no estaban casados". Del diario El País (2005c, p. 1-2). Por otra parte: "La sociedad uruguaya está dividida prácticamente por la mitad en cuanto a su aprobación al matrimonio entre homosexuales. La desaprobación crece definitivamente cuando se consulta sobre la posibilidad de que parejas de personas del mismo sexo puedan adoptar hijos. En cambio, más de 8 de cada 10 uruguayos están de acuerdo con que las uniones de hechos (heterosexuales) tengan los mismos derechos que el matrimonio civil”. Ver diario El País (2005a, p. 16). Finalmente, sobre 1.061.762 hogares, 216.486 son unipersonales. Diario El País (2006a, p. 5).

${ }^{10}$ Del Latín "interstitiŭm” Según la Real Academia Española el vocablo posee tres acepciones: 1) Hendidura o espacio por lo común pequeño que media entre dos cuerpos o entre dos partes de un mismo cuerpo. 2) Espacio o distancia entre dos tiempos o dos lugares, intervalo. 3) En Derecho, espacio de tiempo que, según las leyes eclesiásticas, debe mediar entre la recepción de dos órdenes.

${ }^{11} \mathrm{Al}$ Sistema Internacional lo definimos como aquel sistema constituido por las relaciones vinculantes inter-estatales y por aquellas que establecen y forjan las empresas multinacionales y las grandes corporaciones de la incipiente "Sociedad Civil Mundial", así que los cuerpos organizados de la economía delictiva. Por su parte, "La Economía Mundial" la entendemos como el conjunto de relaciones económicas (productivas, comerciales, financieras, tecnológicas) materiales e inmateriales, lícitas e ilícitas, que se desarrollan a escala planetaria y que son animadas y gobernadas por la lógica de la producción capitalista (ARCE, 2007). 
Norte, Asia, lideran en capacidad productiva, ostentan un poderío comercialfinanciero-tecnológico y son el principal destino de los más importantes flujos de la inversión directa extranjera mundial. En el otro polo, el espacio ex Soviético, el Medio Oriente, África y América Latina luchan y compiten en los intersticios de la Economía Mundial.

En ese contexto de los 18 Estados-Nación que conforman la América Latina (PNUD, 2004), el 90\% de la producción de bienes de uso final y el 85,5\% de la población se concentran en Brasil, Méjico, Argentina, Colombia, Chile, Venezuela y Perú. Alrededor de los dos tercios de su comercio exterior $(\mathrm{X}+\mathrm{M})$ son realizados por las grandes economías de la región: Méjico y Brasil. En la clasificación mundial de la inversión directa extranjera, sólo Brasil figura entre los 10 Estados más importantes, sea tanto en el origen como en el destino de la I.E.D. En este universo, Uruguay representa el $0,7 \%$ del P.B.I. de la región y el 0,6\% de su población.

Analizando la región desde los bloques geo-económicos, el Mercado Común del Sur es el de mayor "peso" socio-económico en América Latina: el MERCOSUR; si bien éste no representa más que el 3,7\% del P.B.I. mundial, sin embargo, genera el 49,9\% del P.B.I. latinoamericano; su población que es el 3,6\% de la mundial, representa en cambio, el 45,1\% de la población de América Latina ${ }^{12}$.

Por su parte, el MERCOSUR, en términos de inversión en Ciencia y Tecnología, tiene una pequeña diferencia a su favor, con relación a sus pares como lo son la Comunidad Andina de Naciones, el Mercado Común Centro Americano y la Comunidad del Caribe.

En este universo, Uruguay participa con el 1,4\% del P.B.I. "MERCOSUR”, representa el $1,5 \%$ de su población y el 1,9\% de su comercio exterior respectivamente ${ }^{13}$. En otros términos, el Uruguay es miembro del primer bloque geo-económico - el MERCOSUR - de una región relativamente periférica - América Latina - en la jerarquizada estructura de la economía mundial.

\footnotetext{
${ }^{12}$ Estos guarismos cambian con el ingreso de Venezuela al MERCOSUR (4 de julio de 2006); el mismo pasa a representar más de la mitad del Producto y de la Población Latinoamericana.

${ }^{13}$ Para calcular la parte en el Producto y la Población se tomaron los datos del Cuadro D (en el Anexo); para el Comercio Exterior $(\mathrm{X}+\mathrm{M} / 2)$, calculado con datos de los Bancos Centrales de los 4 páses citados en el Semanario "Búsqueda" del 01-09-05, p. 28.
} 


\section{Algunos rasgos socio-económicos del Uruguay: la población y el producto}

\section{a) La población}

En 1950, la población uruguaya era de 2.595.510 personas, de 2.930.554 en 1985 y es de 3.305.732 en el año 2005. Lejos de la célebre ley de Malthus, la población nacional se multiplicó por 1,3 en los últimos 50 años. En términos comparativos regionales, es la más baja tasa de variación de los recursos humanos registrada en los 18 Estados latinoamericanos en ese mismo período.

Prospectivamente, también el Uruguay conocerá un déficit considerable en este recurso fundamental y constitutivo de la Nación y del Estado que es condittio sine qua non de la perdurabilidad de la sociedad uruguaya, puesto que en sus principales vecinos geográficos y de la región, las tendencias demográficas son relativamente opuestas a la uruguaya.

Algunas de las principales tendencias del comportamiento y de la estructura poblacional uruguaya podrían resumirse en: su magro crecimiento cuantitativo, la emigración, su envejecimiento y, fruto de una redistribución regresiva del ingreso nacional y funcional, el creciente peso de los pobres en la reproducción de los orientales ${ }^{14}$. En efecto, en virtud de que la sociedad uruguaya procesó precozmente una transición demográfica, la población uruguaya creció (y crece) muy lentamente. La fuerte emigración de las últimas dos décadas que expulsó de la estructura social a unos doscientos mil nacionales ${ }^{15}$, mayoritariamente comprendidos entre 25 y 49 años de edad, explican el envejecimiento de nuestra población, con consecuencias económicas, sociales y civilizacionales graves para el presente y el futuro del proceso de reproducción de la sociedad uruguaya ${ }^{16}$.

\footnotetext{
${ }^{14}$ Sobre el tema se puede consultar las informaciones del Instituto Nacional de Estadística (2005). Por un análisis demográfico de la situación y estructura de la población nacional, véase: Juan e Pellegrino (2004, p. 251-268). Y también, la bibliografia citada en el trabajo.

${ }^{15}$ Idem a la anterior.

${ }^{16}$ En el trabajo "Cambio en la familia, demográficos, sociológicos, culturales y económicos", la socióloga y demógrafa, Mariana Paredes, afirmó que el nivel de reemplazo poblacional es de 2.1 por mujer: "en Uruguay, estamos a punto de caer por debajo de ese dígito, y quiere decir que la población no alcanza para reemplazarse a sí misma." (...) "en 1996, esa tasa era de 2.4 por mujer, pero en los últimos cálculos realizados arrojaban un promedio de 2.05 o 2.06.". Citado en el diario
} 
A su vez, el empobrecimiento de la mayor parte de la población nacional acaecido desde el último tercio del Siglo XX, ha hecho que:

“(...) existan diversos indicios que señalan que la reproducción biológica de la población uruguaya descansa cada vez en mayor medida en los sectores más carenciados. De acuerdo con la información censal de 1996, más del $50 \%$ de los nacimientos ocurrían en madres que presentaban al menos una necesidad básica insatisfecha (NBI). Las diferencias de fecundidad por cantidad de NBI son muy claras; el rango de variación va desde 2,2 hijos por mujer en el caso de las mujeres no pobres, hasta 5,7 hijos por mujer en los tramos más carenciados, tres y más NBI (...).

(...) mientras las mujeres con tres o más NBI maximizan su fecundidad a los 19 años (en un claro esquema de fecundidad precoz), la situación se transforma en una meseta extendida en edades mayores para las mujeres con una o dos NBI y llega a un máximo a los 29 años en las mujeres sin NBI (...).”

“(...) En conclusión, la fecundidad de las mujeres más pobres duplica la de las mujeres con NBS, con una brecha de diez años entre los momentos en que ambos grupos maximizan su reproducción (...)"(JUAN, PELLEGRINO, 2004, p. 255-256).

Fundamentalmente localizada en zonas urbanas, con leve supremacía del sexo femenino $(51,6 \%)^{17}$, la población uruguaya se concentra en los departamentos de Montevideo (40,9\%), Canelones (15,4\%), Maldonado $(4,6 \%)$, Salto $(3,8 \%)$, Colonia $(3,7 \%)$, San José $(3,1 \%)$, Rivera $(3,1 \%)$. En cuanto a la distribución del ingreso medio mensual por departamento, es más favorable a los uruguayos radicados en Montevideo, que a aquellos otros nacionales que lo están en el resto del territorio del país.

\footnotetext{
El País (2005d, p. 12).

${ }^{17}$ Excepto en los Departamentos de Durazno, Florida, Río Negro y Artigas. Véase Instituto Nacional de Estadísticas (2005).
} 


\section{b) El Producto}

Luego de la breve descripción del recurso poblacional, pasemos ahora a examinar otro indicador de la economía nacional, como lo es el P.B.I.

Como ya fue mencionado, el valor del producto interno uruguayo representa el 0,6\% del latinoamericano y el 1,4\% del Mercosur. La evolución del PBI en el período 1985-2003 fue de poca significación: expresado en pesos constantes de 1983 se multiplicó solamente por 1,4. Realizando un análisis desagregado de sus componentes y estructura, se verifican las siguientes características de la producción de los bienes finales uruguayos:

1st) Por sector jurídico/institucional, el PBI es fundamentalmente protagonizado por el sector privado; el sector público (gobierno central y empresas públicas) no supera - en las dos últimas décadas - el 10\% del valor total del PBI.

2nd) En función de su localización geográfica, el 85\% de la producción nacional se realiza en 10 departamentos, entre los cuales se destacan, Montevideo (55,2\%), Canelones (7,5\%), Maldonado (4,0\%), Colonia $(3,9 \%)$ y Paysandú $(3,0 \%)$ donde se concentran más de las tres cuartas partes del valor del PBI nacional.

3rd) Según el sector de actividad, en el producto uruguayo predomina la industria manufacturera -aunque en franco retroceso - el comercio (restaurantes y hoteles), los servicios a empresas y las actividades financieras y de seguros.

En su oferta final, las importaciones, representan entre un quinto y un tercio de su total; en su demanda final, la interna sobresale nítidamente, sobre todo en su componente destinado al consumo, especialmente el privado, mientras que la inversión fija sigue siendo extremadamente modesta. Las exportaciones que también representan entre un quinto y un tercio del producto interno, son lideradas por el rubro carne vacuna, le siguen las pieles y cueros, en tercer lugar el arroz y las lanas, aunque el ingreso de divisas por el turismo, es casi similar al del rubro carnes vacunas. Sus principales mercados por destinos geográficos son: el Mercosur, la Unión Europea, los EEUU y Asia. El bloque Mercosur es el primer socio comercial del Uruguay, aunque en el período analizado pierde casi la mitad de la participación en el destino de las exportaciones en favor de la Unión Europea y sobre todo de los 
EEUU, quien casi triplica su parte en el destino de la demanda externa.

Finalmente cabe señalar que según un reciente estudio sobre las exportaciones uruguayas (LAS EXPORTACIONES URUGUAYAS, 2005), su competitividad estructural, que es aquella que se forja a través de la incorporación del conocimiento y de la innovación tecnológica en los procesos productivos (las ventajas dinámicas) (ARCE, 2001, p. 3-37) no ha cobrado significación a través de un aumento en la competitividad intercapitalista e internacional. En efecto, medida de acuerdo al índice de Adelanto Tecnológico (I.A.T.) elaborado por el Programa de Naciones Unidas para el Desarrollo Humano (PNUD) el:

“(...) valor del IAT del Uruguay (...)" “(...) se encuentra rezagado en lo que respecta a su capacidad para exportar productos intensivos en conocimientos, patentar sus invenciones o percibir ingresos por la explotación de sus patentes. Con respecto a la exportación de productos de tecnología alta y media, $68 \%$ de los países de la muestra (72 países) está mejor que Uruguay, lo que lo ubica en el último tramo del ranking de países. En el ingreso recibido por concepto de regalías y licencias el país se encuentra aún peor clasificado (...)” (LAS EXPORTACIONES URUGUAYAS, 2005, p. 12-13).

Antes de analizar en el próximo capítulo los hechos más significativos y las principales medidas adoptadas por el gobierno presidido por el Dr. Jorge Batlle, el lector encuentra un resumen del P.B.I. uruguayo: el total, el del sector público, por departamentos y su composición estructural.

\section{Los acontecimientos más significativos y las medidas más importantes de la administración del Dr. Jorge Batlle}

\section{La Comisión Para la Paz: una obligación ética del Estado y una tarea imprescindible para preservar la memoria de la Nación}

Uno de los hechos más relevantes del período histórico que nos ocupa fue la creación de la Comisión Para la Paz (en adelante la Comisión), cuyo 
objetivo último y más ambicioso era el de: “(...) consolidar la pacificación nacional y sellar para siempre la paz entre los uruguayos (...)"(INFORME FINAL DE LA COMISIÓN PARA LA PAZ, 2003, p. 5).

Tal como había sido anunciado en el discurso del $1^{\circ}$ de Marzo de 2000 en la Asamblea General, y en el proceso inaugurado por las leyes, primero de Amnistía y después la que reconoció la caducidad del ejercicio de la pretensión punitiva del Estado (ver infra 1, nota 11), el Gobierno de coalición presidido por el Dr. Jorge Batlle, creó, por Resolución de la Presidencia de la República No 858/2000 de 9/08 de 2000, una Comisión que debía: “(...) dar los pasos posibles para determinar la situación de los detenidos-desaparecidos durante el régimen de facto, así como de los menores desaparecidos en iguales condiciones (...)" (INFORME FINAL DE LA COMISIÓN PARA LA PAZ, 2003, p. 5).

Presidida por Monseñor Nicolás Cotugno, el Presbítero Luis Pérez Aguirre S.J. (quien habiendo fallecido fue reemplazado por el también Presbítero Jorge Osorio), el señor José D’Elía y los Dres José Claudio Williman, Gonzalo Fernández y Carlos Ramela Regules, la Comisión elevó al Presidente Batlle, el 10 de Abril de 2003, su Informe Final.

En el punto III) Conclusiones Principales en los párrafos 42, 43, 44 se lee:

“(... 42.- Las conclusiones confirman en la enorme mayoría de los casos el contenido de las denuncias recibidas, aportando detalles y nuevos elementos que terminan por ratificar una situación trágica y dolorosa que nuestro país debe asumir con la prudencia y la grandeza propia de su historia. El aporte de la COMISIÓN se limita a verificar la verdad de los hechos que, aún cuando muchas veces fueron negados, deben ser más considerados como parte de la historia oficial. De ahora en más - considera esta COMISIÓN - es responsabilidad de todos procesar y superar, en toda su dimensión y globalidad, un período triste y oscuro de nuestra historia reciente, intentando sentar las bases de una paz final y definitiva. 
43.- La COMISIÓN considera imperativo señalar, en ese sentido, que es tarea de todos ratificar la plena y total vigencia del Estado de Derecho ante toda y cualquier circunstancia que se pueda verificar o invocar. Es necesario aprender y recordar por siempre que no existe diferencia o divergencia que habilite la violencia, el secuestro y la muerte de cualquier origen o signo y que esas manifestaciones deben ser siempre y en todo caso condenadas; la generalidad de la condena, que abarca todas y cada una de las acciones de aquellos años que en nuestro país tuvieron esos objetivos, no debe ignorar que es siempre y en todo caso el Estado quien tiene la obligación suprema de defender determinados valores, afianzar ciertos principios y descartar determinados procedimientos, usando su autoridad y poder con estricto apego a la ley y a los derechos fundamentales de la persona humana.

El ESTADO que abandona esas premisas y admite o tolera la existencia de un aparato represivo que actúa sin control y por fuera de la legalidad, desvirtúa su esencia y arremete principios fundamentales que hacen a la razón de su propia existencia.

44.- La COMISIÓN no puede soslayar que, a pesar de las limitaciones que demarcan sus facultades y cometidos, ha formado convicción plena acerca de las graves violaciones a los derechos humanos perpetradas durante el régimen de facto.

Desde la tortura, la detención ilegitima en centros clandestinos, hasta llegar a los casos más graves de desaparición forzada, se constata la actuación de agentes que, en el ejercicio de su función pública, obraron al margen de la ley y empleando métodos represivos ilegales.

La COMISIÓN se permite subrayar, por último, que nadie está habilitado o autorizado, en ninguna circunstancia, a violar o desconocer los derechos humanos fundados en la propia existencia y dignidad de la persona. (...)" (INFORME FINAL DE LA COMISIÓN PARA LA PAZ, 2003). 
Así, la Comisión pretendió laudar definitivamente, para los familiares de los detenidos desaparecidos, para las asociaciones defensoras de los DDHH, para la ciudadanía toda y para la Historia y Consciencia Social y Política de la República, la naturaleza del régimen dictatorial cívico-militar que monopolizó el poder entre el 27 de Junio de 1973 y el 1º de Marzo de 1986. Aunque la Comisión no lo califica expresamente al régimen cívico-militar, su naturaleza jurídico/política y sus métodos de gobierno fueron los de un Terrorismo de Estado.

La Comisión clasificó las denuncias de personas detenidas-desaparecidas en cuatro grupos: a) denuncias sobre personas presuntamente desaparecidas en nuestro país; b) denuncias sobre ciudadanos uruguayos presuntamente desaparecidos en Argentina en particular y en el exterior en general; c) denuncia sobre hijos de personas detenidas o presuntamente desaparecidas que habían sido secuestrados y entregados a otras personas; d) denuncias sobre cuerpos aparecidos en las costas de nuestro país.

En todos los casos examinados, pero fundamentalmente para el caso de los detenidos-desaparecidos uruguayos en el Uruguay, la Comisión confirma:

“(...) 26 denuncias -3 anteriores incluso a Junio de 1973 y 23 posteriores, en función de que existen elementos de convicción coincidente y relevantes que permiten asumir que las personas que se individualizan en Anexo No 3.1 fueron detenidas en procedimientos no oficiales o no reconocidos como tales, fueron sometidos a apremios físicos y torturas en centros clandestinos de detención y fallecieron, en definitiva, sea como consecuencia de los castigos recibidos -en la enorme mayoría de los casos- o como consecuencia directa de actos y acciones tendientes a provocar su muerte en algún caso excepcional (...).”

“(...) Los antecedentes de las personas fallecidas evidencian que la enorme mayoría de ellas no participaba en forma directa en actos de violencia ni integraban organizaciones subversivas. La fecha de sus muertes pone de manifiesto, por su parte, que la mayoría de ellas se verificaron después que la sedición había sido desarticulada y derrotada y cuando sus integrantes se hallaban detenidos en establecimientos de reclusión (...)" (INFORME FINAL DE LA COMISIÓN PARA LA PAZ, 2003, p. 17-18). 
A pesar de y como lo señala expresamente el Informe Final, la Comisión trató en: “(...) definitivas no de lograr "una verdad”, o la "verdad más conveniente", sino solamente la "verdad posible", (...)" (INFORME FINAL DE LA COMISIÓN PARA LA PAZ, 2003, p. 15).

Esa "verdad posible" fue y es naturalmente incompleta, porque es probable que no todos los casos de personas detenidas-desaparecidas fueron denunciados, o, no todas las denuncias fueron aclaradas, y finalmente, no todas las victimas del horror y del terror del Estado pudieron ser contemplados por la Comisión. Pero en una perspectiva histórica, la labor de la Comisión para la Paz y su intento de reparar éticamente la responsabilidad del Estado de Derecho y preservar la memoria de la Nación, es un hecho político, cultural y civilizacional de una magnitud invalorable, que cobrará, posiblemente con el transcurso de los años, una significación aún trascendental en la conciencia cívica y política de los uruguayos ${ }^{18}$.

La voluntad del Presidente Batlle y de los miembros de la Comisión Para la Paz de intentar comenzar a sellar dignamente la "Paz entre los uruguayos" fue y es uno de los temas más sensibles para la ciudadanía nacional. En ese tema, la imagen y popularidad del Presidente fueron muy favorables, pero en cambio, en el plano económico y social la percepción general de la población y la evolución de los indicadores que tradicionalmente "leen" une estructura socioeconómica -nivel de actividad, inversión, empleo, distribución del ingreso, tipo de cambio, resultado fiscal, etc - era de preocupación, perplejidad y desconfianza ${ }^{19}$.

\footnotetext{
${ }^{18}$ El reconocer públicamente la naturaleza terrorista del Estado uruguayo, no es un hecho sociopolítico ni menor ni banal en la historia política de la República. Piénsese por ejemplo, que en la dictadura encabezada por el Dr. Gabriel Terra (1933-1942), se persiguieron, se detuvieron y se desterraron a muchos ciudadanos considerados por este régimen como sus enemigos, pero ellos, así como el conjunto de los ciudadanos no sufrieron ni conocieron la aplicación sistemática y organizada del ejercicio monopólico de la violencia del Estado. O también, en las violentas y traumáticas décadas del militarismo (1876-1890), y cabría preguntarse, si ¿la violencia de aquellos gobiernos podría ser, o no, asimilada a la del terrorismo de Estado? Finalmente, a casi 176 años del episodio de "Salsipuedes", los uruguayos se siguen interrogando y debatiendo acerca de si aquella masacre puede ser calificada como un genocidio perpetrado por un Estado con la intención de destruir total o parcialmente a un grupo nacional, étnico, racial, o religioso.

Véase a titulo solamente ilustrativo, por ejemplo, el diario La República del 24-01-06, p. 8-9, y también el semanario Búsqueda del 05-01-06, p. 41-42.

${ }^{19}$ La empresa Factum elaboró un índice de imagen de la gestión del presidente Batlle. Para el año 2002, en un rango entre 0 y 100, en Enero la imagen del presidente recogió un valor de 49 puntos, pero pasó a 23 en Octubre del mismo año. Véase Anuario El Observador (2002-2003, p. 30).
} 


\section{La economía política del espejismo liberal}

La administración de coalición blanqui-colorada inició su gestión económica utilizando el mecanismo previsto en el artículo 168 de la Constitución, mediante el cual, el Poder Ejecutivo envió al Parlamento dos proyectos de ley con carácter de Urgencia. El primero, culminó con la aprobación de la ley No 17.243 (29.06.2000); el segundo, con la ley No 17.292 (25.01.2001). En la primera de esas leyes, el gobierno se proponía: * Fomentar la inversión, el empleo y la agropecuaria (en los 2 casos reduciendo y/o exonerando los aportes patronales al BPS).

* Regular algunos aspectos impositivos para los pequeños y medianos empresas.

* Explicitar las normas referidos a la defensa de la competencia.

* Crear sociedades anónimas de garantía recíproca (para facilita al crédito).

* Introducir la informática en la educación nacional (mediante la devolución del IVA por las compras respectivas).

* Asociar con capitales privados, al Puerto de Montevideo, en la administración construcción, conservación y explotación de una Terminal de contenedores en dicho puerto.

* Mejorar la Administración de los Entes Autónomos, los Servicios Descentralizados y los Gobiernos Departamentales, autorizándolos a realizar contratos de arrendamientos con opción a compra ("leasing operativo"); racionalizar la ejecución presupuestal de las empresas públicas a través de informes semestrales.

* Introducción del expediente electrónico para todos los trámites administrativos (Sistema Informático del Estado).

* La descentralización de los emprendimientos productivos, mediante su localización en el interior del País, activándose la Comisión Sectorial prevista en el Artículo 230 de la Constitución de la República - literal B, inciso quinto).

* Modificar el capital mínimo para la constitución de una Administradora de Fondos de Ahorro Provisionales.

* Modificar algunos artículos y exigencias para las sociedades comerciales.

* Aumentar los recursos humanos para el Ministerio del Interior destinados a la Seguridad Ciudadana (Capítulo XII). 
* Modificar la legislación Penal (Capítulo XIII).

* Creó el Ministerio de Deporte y Juventud para asesorar al Poder Ejecutivo y proponer políticas nacionales en la materia.

En la segunda ley de Urgencia, el gobierno intenta nuevamente:

* Fomentar el empleo (fijando en 0\% el aporte patronal jubilatorio al BPS, entra el 01.01.01 al 31.12.01) y de un $75 \%$ para el sector construcción (por el mismo período),

Y además:

* Encarga a la Auditoria Interna de la Nación, la fiscalización de las Sociedades Comerciales asociados a los Entes Autónomos y Servicios Descentralizados de dominio industrial y comercial.

* Crea en la orbita del Tribunal de Cuentas la Escuela de Auditoria Gubernamental, el nuevo servicio debe fortalecer el proceso de captación de personal y mejorar la gestión y transparencia del Estado.

* Crea dos nuevos juzgados letrados de Concursos (civiles, concordatos, moratoria de sociedades anónimas, quiebras, liquidaciones judiciales en el departamento de Montevideo).

* Estimula y regula el régimen de adopción de menores por parte de los funcionarios públicos, quienes estando afiliados al BPS, gozarán por ese motivo de 6 semanas de licencia especial.

* Modifica los plazos legales para los recursos administrativos previstos en el artículo 318 de la Constitución de la República.

* Encarga al Ministerio de Vivienda, Ordenamiento Territorial y Medio Ambiente - junto al BPS - la formulación de políticos de viviendas para los jubilados y pensionistas.

* Estimula la fusión de los cooperativos de vivienda (ley No 13.728).

* Encuadra, dentro la ley de Urgencia y de las normativas municipales, las urbanizaciones desarrolladas en zonas urbanas, suburbanas, rurales y las considera comprendidas en el régimen de la propiedad horizontal.

* Modifica el Registro de Aspirantes a viviendas de emergencia (RAVE).

* Creó el Registro Nacional de Aeronaves.

* Autorizó a quien compre gas natural al por mayor - y teniendo un consumo en promedio anual no inferior a 5.000 metros cúbicos - a adquirirlo sea a un proveedor nacional o extranjero. 
* Modificó el artículo 2 de la ley 15.291 relativo a la definición y competencias de las zonas francas.

* Regula el fomento del deporte, definiendo qué se entiende por clubes deportivos en general, de su capital, de los accionistas y de su administración y creó un programa de Desarrollo y Protección de Talentos Deportivos.

* Ordenó que, en la Cooperativa Nacional de Productores de Leche CONAPROLE -, el control interno fuese ejercido por una Comisión Fiscal Honoria e integrada por 3 miembros.

El gobierno expresaba a través de esas leyes con carácter de Urgencia, la necesidad de enfrentar rápidamente un cuadro nacional y regional desfavorable para la economía nacional signado por el encadenamiento de: - Los efectos aleatorios (a veces positivos o negativos), de los diferentes regímenes cambiarios adaptados por los sucesivos gobiernos en el mercado monetario/financiero, cuyas reglas son definidas en el espacio financiero mundial ${ }^{20}$, al cual el sistema bancario uruguayo fue integrado en 1974, particularmente, en la última década, en la cual, el llamado "atraso cambiario", castigó las exportaciones y favoreció las importaciones -sobre todo las de los bienes destinados al consumo final - sosteniendo un déficit crónico en la balanza comercial.

- La devaluación de la moneda brasileña acaecida en 1999, que aumentó las dificultades de comercio exterior nacional.

- La aparición de un foco de aftosa con consecuencias negativas para la producción y exportación del sector de carnes rojas (abril 2001).

- La devaluación de la moneda argentina que conllevó el fin de la convertibilidad ( 1 peso = 1 dólar, en diciembre 2001) y sumergió, definitivamente a la economía y sociedad uruguaya en una crisis productiva, comercial, financiera, fiscal y social, sin precedentes históricos.

\section{El quiebre liberal, o, cuando el año “(...) 2002 fue el más traumático que vivió Uruguay en los últimos 100 años (...)"21}

La administración de coalición presidida por el Doctor Batlle inició su gestión con un nivel de actividad decreciente y un también crónico déficit

\footnotetext{
${ }^{20} \mathrm{Al}$ respecto véase Chesnais (1997).

${ }^{21}$ Frase del Presidente Batlle en el almuerzo de ADM el 18-12-2002. Citado en Anuario El Observador (2002-2003, p. 30).
} 
en las finanzas del gobierno; a ello se imbricó los efectos de la modificación de los regímenes cambiarios en Brasil y en Argentina, que fueron negativos, pues el gobierno no quiso modificar el valor de su tipo de cambio. La acción combinada de esos elementos desencadenó la crisis bancaria y financiera, la que demostró por otra parte, el denso, notable y simultáneo funcionamiento de los distintos mercados monetarios "nacionales", en el unificado, desregulado y jerarquizado espacio financiero mundial ${ }^{22}$. En ese mercado global, tanto el valor como el volumen de las monedas líderes (dólar USA, Euro), como sus precios (tasa de interés, tasa de cambio) son prácticamente poco influenciables para las producciones y monedas sin poder de mercado, como es el caso, no sólo del Uruguay, sino de la mayor parte de las sociedades y Estados de la economía mundial.

La economía nacional, su mercado monetario y su sistema bancario, fueron incorporados al espacio financiero mundial por el gobierno dictatorial cívico-militar ${ }^{23}$ en 1974; la creación de una plaza financiera exigió, y exige, un importante ingreso de capitales monetarios, remunerados por altas tasas de interés y por la seguridad del secreto bancario que ofrece el sistema uruguayo. La internacionalización y el carácter especulativo del capital dinero, ya había provocado la gigantesca y fraudulenta crisis bancaria de 198224; en el 2002, bajo otro contexto y otras circunstancias, provocará nuevamente otra crisis, puesto que el uso de esos depósitos - como también había sido el caso 20 años antes - no fueron asociados a la producción de más y nuevos bienes económicos o mercancías, financiando la inversión productiva, en el sentido clásico del término, sino a su auto-valorización en el espacio financiero mundial. Sin el rigor de un teórico de la economía monetaria, el Presidente Batlle definió nítidamente el "talón de Aquiles" de la política económica de la cual fue, y es, une ferviente partidario. Analizando la crisis que rodeó el fraude operado en el Banco Comercial, el Presidente Batlle sostenía:

“(...) Si el gobierno dejaba caer al Banco Comercial hubiera sido una terrible tragedia para la economía. Hay patriotas uruguayos que viven en

\footnotetext{
${ }^{22}$ Ver recuadro 2.

${ }^{23}$ Ver recuadro 2.

${ }^{24}$ Este fenómeno fue conocido, entonces, como la operación "compra de carteras". Al respecto se puede leer: Stolovich (1986).
} 
casas ricas y se movilizan en autos $4 \mathrm{x} 4$ pidiendo que los que no tenemos dinero a plazo fijo, como usted y yo, les solucionemos el problema. Esas personas que durante diez años solicitaron que fueran recibidos sus ahorros para ganar intereses importantes, lo hicieron sabedores de que los colocaban fuera del Uruguay. (...) Durante diez años quedaron muy contentos y calladitos la boca fueron a cobrar los intereses. Ahora lo que están pretendiendo es acusar al BCU para ver si pueden pedirle a Uruguay que les pague los intereses (depósitos) que sacaron -en una actitud anti-patriota - del país." ${ }^{25}$.

\section{La "corrida" bancaria, el fantasma del "corralito" y el posible default (Diciembre 2001-Julio/Setiembre 2002)}

La insostenibilidad de la arquitectura económica-financiera aplicada por los auto-proclamados liberales argentinos en 1991 con el régimen de cambios fijos, comenzó a oficializarse, cuando el líder ideológico y mentor del Plan de Convertibilidad, el ministro de Economía Domingo Cavallo, decretó la imposibilidad de retirar sumas mayores de 250 dólares de los bancos argentinos (el 01.12.01) ${ }^{26}$.

En Uruguay, el retiro abrupto de los depósitos del Banco de Galicia Uruguay por un monto estimado en unos 500 millones de dólares (fines de diciembre 2001-enero 2002-) y la posterior negativa de asistencia del Banco Central del Uruguay (BCU) a esa institución, no sólo determinó que la autoridad monetaria central decidiera su intervención (13.02.02), sino que alentó que otros ahorristas comenzaran a retirar sus depósitos frente a la eventualidad que los bancos concernidos no tuvieran disponible y que el Estado uruguayo no pudiera tampoco, responder en última instancia, a los valores en juego. Así, en el primer semestre del 2002, entre 6.500 y 7.000 millones de dólares fueron retirados del sistema bancario (casi la mitad de todos los depósitos, un valor equivalente al $42 \%$ del PBI de ese ańo, o, a casi tres veces el valor de las exportaciones de ese mismo año.

\footnotetext{
${ }^{25}$ Declaraciones efectuadas el sábado 17 de agosto de 2002, en el departamento de Río Negro, con motivo de un homenaje al Doctor Mario Carminatti. En Anuario El Observador (2002-2003, p. 30).

${ }^{26} \mathrm{La}$ indisponibilidad de los depósitos es una confiscación temporal de los mismos; esta operación fue bautizada popularmente con la expresión de "el corralito" en la República Argentina.
} 
El gobierno comenzó a asistir a los bancos a los efectos de paliar la "corrida" y dar muestras de la solidez de los mismos, aún y a pesar que algunos de ellos actuaron irregular y fraudulentamente (Banco Comercial, Banco Montevideo, que cerraron junto al Pan de Azúcar y al Banco de Crédito). La crisis bancaria se desató; mientras los activos de reserva del BCU descendieron de 3.500 millones de dólares en diciembre de 2001 a casi 500 en junio de 2002, la desconfianza se instaló en el mercado y, las desafortunadas declaraciones del Presidente ${ }^{27}$ no hicieron más que apuntalar las incertidumbres y el temor de los ahorristas y de la ciudadanía en general.

El 20 de junio, el gobierno devaluó la moneda nacional, abandonó la banda de flotación y sumergió a la economía en la depresión y, la pobreza y la exclusión marcaron con su impronta el ingreso del Uruguay al siglo XXI (ver infra Capítulo 1).

El 19 de julio, el gobierno relevó a los directores del BCU, pues en el sistema político y en buena parte de la ciudadanía, se percibía que las autoridades bancocentralistas habían actuado con omisión en y frente a la crisis bancaria ${ }^{28}$.

El 22 de julio, luego de una interpelación en el Senado de la República ${ }^{29}$, renunció el ministro de Economía, Contador Alberto Bensión y lo sustituye el senador Doctor Alejandro Achugary.

El 30 de julio, se decretó feriado bancario que se levantó el 5 de agosto. La cesación de pagos era evidente como inminente. En el ínterin, el gobierno logró un acuerdo in extremis con el FMI, gracias al excepcional apoyo del Presidente Bush $^{30}$, quien autorizó que el Tesoro americano habilitará un "crédito puente" de 1.500 millones dólares, que eran necesarios para implementar una formula que evitará el default. La misma consistió en la

\footnotetext{
27 Ver cronología de la segunda parte.

${ }^{28}$ Luego de una "cumbre' entre los ex-presidentes Lacalle y Sanguinetti, los directores $\mathrm{Cr}$ Cesar Rodríguez Batlle, Dra Eva Holz (colorados) y Cra Rosario Mederos (Partido Nacional) fueron sustituidos por el Ec. Julio de Brum, Dr. Miguel Vieyttes (partido colorado) y Andrés Pieroni.

${ }^{29}$ El 11 y 12 de lulio, el Senador Alberto Couriel, en nombre el Encuentro Progesista - Frente Amplio interpeló el ministro Cr Alberto Bensión. Véase diario de Sesiones de la Cámara de Senadores, n. 185, Tomo 412. También el capítulo V de Couriel (2004).

${ }^{30}$ Las intensas y frenéticas negociaciones acaecidas en esos días y los protagonistas involucrados en las mismas, son relatados minuciosamente en capítulo 12 de Paolillo (2004). En dicho trabajo se analiza y describe las vicisitudes del presidente Batlle, de su gobierno y del sistema político en general, frente a la crisis desatada entre diciembre 2001 y agosto 2002.
} 
creación de un Fondo de Estabilidad del Sistema Financiero (ley 17.523), por el cual se realizó:

a) la reprogramación a tres años de los depósitos a plazo fijo en moneda extranjera en los bancos públicos (BHU, BROU) existente al 30.07.02;

b) la asistencia a los bancos (públicos y privados) para que cubrieran sus cuentas corrientes y las Cajas de ahorro, a la vez que cesó definitivamente la asistencia a los bancos con dificultades;

c) la suspensión de cuatro bancos - Comercial, De Crédito, Caja Obrera y de Montevideo- y la Cooperativa CAYCU.

El 5 de agosto, con el levantamiento del feriado bancario se liquidaron sueldos y pasividades, se habilitaron las cuentas corrientes y las cajas de ahorro.

El 28 de octubre, el Partido Nacional se retira de la coalición de gobierno (ver infra Capítulo 1, nota 2, página 9), y la administración Batlle, continuará -ahora sólo con el apoyo del Partido Colorado - de gestionar y en condiciones leoninas, la crisis que según las propios palabras del Presidente fue: “(...) la más traumática de los últimos 100 años (...)"31.

En este contexto de crisis nacional y regional, cabe mencionar también como ejemplos de disposiciones relevantes en materia productiva y comercial la orientación que asumió el gobierno de Batlle tratando de enfrentar los problemas intrínsicos al MERCOSUR mediante la búsqueda de nuevos mercados, reabriéndose otra vez en la historia reciente de la política nacional, un debate acerca de la inserción internacional del Uruguay. Así la política internacional cobró otra dimensión en el período que nos ocupa en este texto, y es por ello que es necesario recordar la firma de un Tratado de Promoción y Protección de Inversiones con Finlandia (21 de marzo de 2002), el Protocolo sobre Promoción y Protección de Inversiones provenientes de Estados no parte del MERCOSUR (9 de agosto del 2002), la firma de un Tratado bilateral de Protección de Inversiones Uruguay-Estados Unidos ${ }^{32}$ (2005), y el Tratado de Libre Comercio Uruguay-Méjico (15 de julio de 2004), proceso este que se analiza más profundamente en la segunda parte de este trabajo.

\footnotetext{
${ }^{31}$ Ver nota 9.

${ }^{32}$ Las negociaciones sobre dicho tratado culminaron casi simultáneamente a la finalización de la Administración del Gobierno de Batlle. Fue ratificado, con leves modificaciones, por la nueva Administración y el nuevo Parlamento en el gobierno a partir del $1^{\underline{a}}$ de marzo de 2005.
} 


\section{La deuda, las reformas estructurales y otras medidas de política económica}

En el transcurso del año 2002 mientras los ahorristas retiraban sus depósitos y el gobierno no sólo asistía con fondos públicos a los bancos, sino que también negociaba con el FMI, el otorgamiento de créditos para evitar la cesación de pagos, es decir, el default.

Como sucedió en la crisis de 1982, ésta vez también el Estado asumió la deuda privada: la deuda pública pasó del 40,8 \% del PBI en 2002 a 100,9\% en el 2004. Ello fue el resultado de la estrategia que la administración Batlle y el FMI consensuaron en las sucesivas Cartas de Intención que firmaron entre marzo de 2002 y marzo de $2005^{33}$. En y con ellas el gobierno no sólo encontró los recursos financieros para sobrellevar la crisis del 2002, sino que también allí se plasmaron las grandes orientaciones en materia de política económica, que el gobierno electo en las elecciones del 2004 y en ejercicio desde el $1^{\circ}$ de marzo de 2005, debería tener en cuenta.

En efecto, en el transcurso del año 2003, el gobierno y el FMI convinieron en proceder en el reperfilamiento de los vencimientos que postergara las amortizaciones, esperando un mayor nivel de actividad, fruto del aumento de las exportaciones, más competitivas después de la fuerte devaluación del 2002. El mecanismo puesto en marcha consistió en una operación de Canje de los títulos de deuda, que los tenedores poseían -casi las $3 / 4$ partes eran residentes - en moneda extranjera y emitidos a más de un año y que vencían entre 2003-2007. El monto a negociar era de 5.400 millones de dólares (casi la mitad de la deuda pública total). En mayo de ese mismo año, el 93\% de los tenedores de esos títulos accedieron cambiarlos por nuevos títulos con plazos mayores de vencimiento.

Así, el gobierno logró postergar los vencimientos de la deuda pública y transfirió dicha problemática, entre otras, para el próximo gobierno.

En lo que atañe a las llamadas reformas estructurales consensuadas por el gobierno y el FMI se destacan, grosso modo:

a) la transferencia de los créditos de difícil recuperación -tanto en la banca

\footnotetext{
${ }^{33}$ Un primer momento fue la Carta Intención firmada en marzo del 2002, vigente por dos años y cuyo plazo se extendió a marzo de 2003 y luego a marzo de 2005. Por una lectura más detallada sobre el tema véase: Informe de Coyuntura (2002-2003; 2003-2004).
} 
pública como la privada - a las sociedades fiduciarias creadas por la ley 17.703 del 27 de octubre de 2003 para intentar sanear, así, al sistema bancario.

b) reforma de las Cajas de Jubilaciones Militar, Policial y Bancaria.

c) reestructura de la Dirección General Impositiva, mediante la creación de la Unidad de Grandes Contribuyentes a los efectos de mejorar la recaudación fiscal, reduciendo el fraude y la evasión fiscal.

d) en setiembre de 2002, mediante la Ley de Reactivación Económica (17.555), el gobierno puso en práctica una serie de medidas a los efectos de estimular una deprimida actividad económica. Entre las disposiciones más importantes a mencionar en dicha Ley se encuentran:

* la facultad que se le otorga al Estado, los Entes Autónomos, los Servicios Descentralizados y los Gobiernos Departamentales a recibir iniciativas relativas a actividades susceptibles de ser ejecutadas directamente por los organismos referidos o a ser concesionadas de acuerdo con las normas constitucionales y legales en vigencia, sea a impulso de parte o mediante invitación de oficio (art. 19);

* la puesta en marcha del Convenio Contrato suscrito con el Ministerio de Transporte y Obras Públicas (del 5 de octubre de 2001), que implicó la autorización a la Corporación Nacional para el Desarrollo a ceder totalmente el contrato de concesión o a enajenar a empresas radicadas en el país, o a organismos internacionales de crédito de los que la República forma parte, hasta el $100 \%$ del capital accionario de la Sociedad Anónima formada por aquel para actuar como concesionario de la llamada "Megaconcesión" (art. 28);

* la Declaración de Interés Nacional de las siguientes zonas turísticas:

a) costa sobre el Océano Atlántico, desde el balneario "Coronilla" hasta el de "Punta del Diablo" (en Rocha), incluyendo el Parque "Santa Teresa".

b) el área aledaña a la Central hidroeléctrica Constitución - Palmar (Soriano).

c) la zona de "Rincón del Bonete" (Tacuarembó).

d) el parque "Bartolomé Hidalgo" (Soriano).

e) el área aledaña a la Central hidroeléctrica de "Baygorria" (Departamentos de Durazno y Río Negro) art. 36.

Como se puede apreciar, la debacle económica-financiera del año 2002, 
lejos de cuestionar las orientaciones liberales que guiaron las principales decisiones de la administración Batlle, las reforzaron. Del análisis de las leyes de urgencia, de Reactivación Económica y los clásicos compromisos establecidos en las Cartas de Intención con el FMI, se desprende claramente la voluntad política de mantener las grandes orientaciones liberales, a saber: crear y estimular la competencia intercapitalista, para que, fundamentalmente el sector privado, nacional y extranjero, organice la producción la acumulación, siendo el mercado, quien decide acerca de cómo afectar los recursos de la sociedad y formar los precios. Por su parte, el Estado y el sector público, deben registrar saldos positivos en sus finanzas, contribuyendo a controlar la inflación, al mismo tiempo que, mientras se prosigue su retiro del mercado, se le reserva, fundamentalmente, para asumir las enormes - y a veces fraudulentas - deudas privadas.

\section{A modo de conclusión}

El gobierno presidido por el Dr. Batlle, primero en coalición con el Partido Nacional, después sólo con el apoyo del Partido Colorado, prometió un auténtico crecimiento económico, proponía una presencia más notoria del Uruguay en las relaciones internacionales, una revolucionaria modernización capitalista del aparato productivo (público y privado), para modelar, así, la inserción del Uruguay en la nueva economía y en la sociedad del Siglo XXI: la sociedad del conocimiento.

Las particulares y determinantes condiciones del mercado y de la competencia intercapitalista - regional y mundial - y las propias a su administración, sumergieron a la sociedad uruguaya en la crisis más traumática que conoció nuestro país en los últimos cien años.

Como fue señalado (1. - página 18), la sociedad uruguaya conoce cambios que provienen desde antes del período histórico que concierne a la administración Batlle.

En los últimos cuarenta años, es, fundamentalmente, en el campo de las ideas propias a la economía política, que el liberalismo y su proyecto, caro no sólo al presidente Batlle, sino también a un importante segmento de las elites (políticas, gremiales empresariales, académicas/universitarias, de los medios de comunicación), viene transitando y ganando terreno y adeptos. 
En ese sentido, la administración Batlle, debe ser analizada y evaluada como un paso más en la larga e irresistible marcha liberal, iniciada en la década de 1960-1970. Recordemos, aunque sea brevemente, algunos grandes acontecimientos que jalonaron el progresivo avance del proyecto liberal.

Con el advenimiento del primer gobierno del Partido Nacional en 1959 - poniendo así fin a casi un siglo de gobiernos del Partido Colorado -, se aplica la Ley de Reforma Monetaria y Cambiaria, por la cual se derogan los cambios múltiples ${ }^{34}$, se instauran los mecanismos del mercado en el campo monetario-financiero, se eliminan impuestos y subsidios y, se devalúa la moneda nacional (de 1 dólar = 4,11 pesos uruguayos, a 1 dólar = 11 pesos uruguayos).

Después de un poco más de una década, cuando los movimientos guerrilleros habían sido militarmente derrotados (1972), y luego de haber sometido toda oposición, la dictadura civico-militar (golpe de Estado del 27 de junio de 1973), mientras aplicaba una política de terrorismo de Estado en el campo social-político-cultural, liberalizaba las fuerzas del mercado, dando un nuevo impulso a las orientaciones enmarcadas en la Ley de Reforma Monetaria y Cambiaria, y, sobre todo, a las proposiciones liberales contenidas en el Plan Nacional de Desarrollo (1972-1977), lo que indicaba claramente, la derrota intelectual y política de los enfoques estructuralistas y keynesianos contenidos en el Plan Nacional de Desarrollo Económico y Social, elaborado en los ańos 60, por la Comisión de Inversiones y Desarrollo Económico - CIDE -.

Así, desde 1974, se decreta la liberalización del mercado de cambios y de movimiento de capitales; se procesa otra vez un descenso de los niveles arancelarios para las importaciones; en 1978, el liberalismo ingresa al sector agropecuario y al sector de la industria cárnica roja; so pretexto de combatir la inflación se aplica la famosa "tablita", y se clausuró el estatal Frigorífico Nacional.

\footnotetext{
${ }^{34}$ Este mecanismo se instauró por la Ley del 29.01.1931, que otorgó, además, el monopolio de las divisas del comercio exterior al BROU. Al control de los cambios múltiples se sumaron las siguientes disposiciones: la Ley del 06.08.1931 (que aumentó los derechos de importación advalorem, de 31 a 43\%); la Ley del 20.08.1931 (que prohibió la importación de bienes de lujo); y la Ley del 20.01.1932 (que suspendió el pago de las amortizaciones de la deuda externa pública). Este conjunto de disposiciones constituyeron el núcleo duro de las medidas proteccionistas, que permitirán en la década del 1940, el crecimiento económico en base a la industria substitutiva de importaciones.
} 
Con la restauración democrática, y durante la primera presidencia del Dr. Julio María Sanguinetti (1985-1990), se intentó comenzar a resolver el tema de la violación de los derechos humanos, a renegociar la inserción internacional del país, a administrar el enorme endeudamiento generado por el fracaso de la política monetaria cambiaria (1978-1982), todo ello en un contexto de políticas económicas enmarcadas en un "progresivo" liberalismo, haciendo acento en el esfuerzo exportador (Ley de zonas francas, CND, etc.).

Con la asunción del gobierno del Partido Nacional (1990-1995), dirigido por el Dr. Luis Alberto Lacalle, las ideas liberales alcanzaron un punto culminante, tanto a nivel ideológico como en el terreno de la praxis, vista la tentativa de rediseñar el funcionamiento económico y social del Uruguay, tal cual se fue formulando desde principios del Siglo XX. En este período, grosso modo, el proyecto liberal avanzó a través de la firma del Tratado de Asunción por el cual se creó el Mercosur. Éste, en su preámbulo y en sus propósitos y principios, indica claramente que el proceso de integración que se ponía en marcha, sería una obra, principalmente, de las decisiones y riesgos que los agentes adoptarían en una competencia en la cual, reinaría la menor de las restricciones posibles. Es por ello que, también se proclama en ese texto la libre circulación de bienes, servicios y factores productivos, el establecimiento de un arancel externo común, y, la adopción de una política comercial común frente a terceros estados, así que la armonización de las legislaciones. Ello, entre otros tópicos, implica que cada Estado Miembro deba resignar soberanía arancelaria y aduanera, así que restricciones no arancelarias, en aras de construir, primero, une zona de libre comercio (19901995), y después el Mercado Común.

A su vez, en su artículo 1, se pregona que la coordinación de las políticas macroeconómicas y sectoriales entre los estados partes, comprende: comercio exterior, agrícola, industrial, fiscal, monetaria, cambiaria y de capitales, de servicios, aduanera, de transporte, comunicaciones a los efectos de asegurar condiciones adecuadas de competencia entre los estados partes. Coherente con estos principios liberales, el gobierno del Dr. Lacalle, cerró la Industria Lobera y Pesquera del Estado (ILPE), en 1991, y aprobó la Ley 16.211 (del 01.10.2001), de Servicios Públicos Nacionales, a los efectos de hacer jugar 
plenamente los mecanismos de la competencia, eliminando los monopolios, legales y/o naturales. Por esta ley se facultaba al Poder Ejecutivo a conceder $\mathrm{u}$ otorgar permiso a empresas privadas para la ejecución de servicios públicos. La cesión de derechos de uso, usufructo y la constitución de derechos reales o personales sobre los bienes (muebles o inmuebles) del patrimonio estatal, implicaba desmantelar los Entes Autónomos y Servicios Descentralizados, arquitectura sobre la cual se edificó a lo largo del Siglo XX, el sector público y la economía pública en el Uruguay.

Sometido a consulta popular - referéndum - la Ley no pudo ser aplicada. Pero el esfuerzo liberal continuó por otras vías y por otros mecanismos: se privatizó el 51\% del capital accionario de PLUNA (1994), se modificó el sistema de seguridad social (creación de las AFAPS), se desmonopolizaron los servicios del puerto, los seguros, la generación y consumo de energía eléctrica, la producción de alcoholes, y tantas otras actividades procesadas en la segunda presidencia del Dr. Sanguinetti (1995-2000), como las ya analizadas y acaecidas bajo la administración Batlle (Leyes de Urgencia y la de Reactivación Económica).

En diciembre del año 2006, y coincidiendo con la finalización del presente trabajo, se publicó un libro: "Para entender la economía del Uruguay" (CINVE, 2006). En el capítulo 1 (Crecimiento durante el Siglo XX - p. 27 a 60), se describe la evolución del crecimiento del PBI per cápita, entre 1900 y 2003, siglo en el cual, creció 1,4\%. En los primeros cincuenta años, el PBI per cápita creció a una tasa promedio anual de $1,87 \%$; en la segunda mitad del siglo, sólo lo hizo a una tasa promedio anual de $0,8 \%$. Analizando más en detalle este segundo período (1955-2003), surge que entre 1955 a 1968, hubo una variación negativa del PBI per cápita (crisis de la industria sustitutiva), y, desde 1968 a 2003, se procesa un crecimiento económico. El mismo está vinculado históricamente a la puesta en marcha de las políticas económicas liberales, lo que en una primera lectura podría interpretarse como un éxito de las mismas. Sin embargo, y a justo título, el trabajo del CINVE, relativiza enormemente tal interpretación, puesto que, en este segundo período, primero la crisis de 1982 y después la del 2002 provocaron, de manera fulminante, pérdidas y costos (económicos, sociales y ambientales) de una magnitud tal que cuestionan las lentas y trabajosas ganancias derivadas de ese frágil 
crecimiento económico del modelo exportador. Es quizás, por ésta y otras múltiples razones que atienden a la calidad y durabilidad del crecimiento económica, base del desarrollo social, que el "Informe de Desarrollo Humano" - año 2005 - del PNUD, clasificó a Uruguay en el puesto número 46, de su IDH, pero en el año 1999, el Uruguay ocupaba el 40. 


\section{Referencias Bibliográficas}

AGLIETTA, Michel; ORLÉAN, André. La Monnaie. Entre violence et confiance. Francia, París: Ed. Odile Jacob, 2002.

AMARANTE, Verónica; VIGORITO, Andrea. Evolución de la pobreza en el Uruguay. Uruguay: Instituto Nacional de Estadística, 2006. Disponible en: www.ine.gub.uy//biblioteca/publicaciones.htm.

ARCE, Gustavo. La evolución económica uruguaya en la década del 80 y algo más. En colaboración. Montevideo-Uruguay: FCU - Fundación de Cultura Universitaria, 1994.

. El capitalismo de la sociedad de la información. La Sociedad de la Información. Montevideo-Uruguay: FCU - Fundación de Cultura Universitaria, p. 5-33, 2001.

. El espacio económico mundial. Una economía política de los pueblos, las naciones y los estados. 2007. 120 p. (publicación en curso).

. El capitalismo de la sociedad de la Información. En: La sociedad de la información. Montevideo-Uruguay: Editorial F.C.U., 2001.

ASTORI, Danilo; LORENZO, Fernando; ABOAL, Diego; NOTARO, Jorge; OLESKER, Daniel; PORTO Luis; VAILLANT, Marcel; VIERA, Carlos. Propuestas de política económica. Montevideo-Uruguay: Ed. Banda Oriental, 2005.

BENSIÓN, Alberto. La crisis del 2002. Mi gestión frente al cataclismo bancario. Montevideo-Uruguay: Ed. Fin de Siglo, 2004.

BÉRTOLA, Luis; BITTENCOURT, Gustavo. 20 años de democracia sin desarrollo económico 1985-2005: miradas múltiples. Montevideo-Uruguay: Ed. Taurus. p. 305-329, 2005.

BERGARA, Mario. Las reglas de juego en Uruguay. El entorno institucional y los problemas económicos. Montevideo-Uruguay: Ed. Trilce, 2003. 
CALVO, Juan José; PELLEGRINO, Adela. 20 años no es nada. En: CAETANO, Gerardo. 20 años de democracia. Uruguay 1985-2005: miradas múltiples. Montevideo-Uruguay: Ed. Taurus, 2005, p. 251-268.

CHESNAIS, François. La mondialisation financière: genese, coût et enjeux. Paris-France: Ed. Syros, 1997.

CINVE. Para entender la economía del Uruguay. Montevideo-Uruguay: Ed. FCU, 2006.

COMISIÓN ECONÓMICA PARA AMÉRICA LATINA. CEPAL. Balance preliminar de las economías de América Latina y el Caribe. Informe Anual. . Objetivos de desarrollo del milenio: una mirada desde América Latina y el Caribe. Informe Anual, ago. 2005.

- Políticas públicas para el desarrollo de sociedades de información en América Latina y el Caribe. Informe Anual, junio. 2005.

COMISIÓN EUROPEA. La Unión Europea, América Latina y el Caribe: una asociación estratégica. Oficina de Publicaciones, 2005. Disponible en: http://publications.eu.int.

CONFERENCIA DE LAS NACIONES UNIDAS SOBRE COMERCIO Y DESARROLLO (CNUCD). Informe sobre las inversiones en el mundo. Informes Anuales.

. Informe sobre el comercio y el desarrollo. Panorama General. . Informe sobre la economía de la información, 2005.

COURIEL, Alberto. La izquierda y el Uruguay del Futuro. 2. ed. MontevideoUruguay: Ed. Banda Oriental, 2004.

DE ARMAS, Gustavo. De La Sociedad Hiperintegrada al País Fragmentado. Crónica del último tramo de un largo recorrido, página 269 a 303, en 20 AÑOS DE DEMOCRACIA. Uruguay 1985-2005. Miradas Múltiples. Bajo la Dirección de Gerardo Caetano. Montevideo-Uruguay: Ed. Taurus, 2005. 
DÍAZ, Ramón. Historia económica del Uruguay. Montevideo-Uruguay: Ed. Taurus. Fundación Bank Boston, 2003.

DISCURSO PRESIDENCIAL del 10 de marzo de 2000. Disponible en: http:// prensa_web@presidencia.gub.uy.

EL OBSERVADOR. Anuario 2002/2003 - 2005/2006. Montevideo-Uruguay. Anuario 2004/2005. Montevideo-Uruguay. . Cambio y crecimiento. Revista Especial, Uruguay, feb. 2005.

EL PAÍS. Montevideo-Uruguay: p. 16, 28 ago. 2005a. 1ra sección. . Montevideo-Uruguay: p. 14, 18 sept. 2005b. . Montevideo-Uruguay: p. 1-2, 13 nov. 2005c. 2da sección. . Montevideo-Uruguay: p 12, 4 dic. 2005d. Primera sección. . Montevideo-Uruguay: p. 5, 18 jun. 2006a. 2da sección. . Montevideo-Uruguay: p. 16, 16 ago. 2006b.

FAROPPA, Luis. Perspectivas para un país en crisis. Montevideo-Uruguay: Ed. Nuestra Tierra, 1970.

FONDO MONETARIO INTERNACIONAL. Perspectivas de la economía mundial. El desarrollo de las instituciones. Sept. 2005. Disponible en: http://www.imfo.org.

GRAU, Carlos; LAGOMARSINO, Gabriel. Estructura tributaria. Su Impacto en la distribución del ingreso de los hogares uruguayos. MontevideoUruguay: Ed. F.C.U., 2002.

INFORME DE COYUNTURA. 2002-2003; 2003-2004. MontevideoUruguay: Ed. F.C.E. y A.

INFORME FINAL DE LA COMISIÓN PARA LA PAZ. Servicio Paz y Justicia Uruguay, 10 abr. 2003. Disponible en: http://www.serpaj.org.uy/serpajph/ documentos/d_copazfinal.pdf. 
INSTITUTO DE ECONOMÍA. Informe de coyuntura (Anuales). Facultad de Ciencias Económicas y Administración, Universidad de la República. Disponible en: http://www.iecon.ccee.edu.uy.

El Uruguay del siglo XXI. Montevideo-Uruguay: Tomo 1: La Economía, Ed. Banda Oriental, 2001.

INSTITUTO NACIONAL DE ESTADÍSTICAS. INE. Estimaciones de pobreza por el método del ingreso 2004. El Uruguay en cifras 2005. Disponible en: http://www.ine.gub.uy.

. El Uruguay en cifras. Montevideo-Uruguay: Ed. INE, 2005. Disponible en: http://www.ine.gub.uy.

JUAN, José Calvo; PELLEGRINO, Adela. Veinte años no es nada. En: CAETANO, Gerardo (Dir.). 20 años de democracia. Montevideo-Uruguay: Ed. Taurus. 2004. (páginas 251 a 268).

LAS EXPORTACIONES URUGUAYAS: evolución y fuentes de competitividad. Montevideo-Uruguay: Facultad de Ciencias Económicas y de Administración, UdelaR, Banco de la República Oriental del Uruguay, Banco del año 2005, nov. 2005.

MACADAR, Luis. Restauración democrática y política económica: Uruguay. 1985-1989. Montevideo-Uruguay: Ed. Banda Oriental, 1992.

NOTARO, Jorge. El problema del empleo en el Uruguay. Diagnóstico y propuestas. Montevideo-Uruguay: Ed. Banda Oriental, 2005.

NACIONES UNIDAS. Informe sobre el desarrollo humano. Anuales, PNUD. Disponible en: http://www.pnud.org.

. Desarrollo humano en Uruguay. 2005. Disponible en: http://www. presidencia.gub.uy.

OFICINA INTERNACIONAL DEL TRABAJO (OIT). Uruguay: empleo y protección social. De la crisis al crecimiento. Santiago de Chile: OIT, 2005.

. Panorama laboral. Lima-Perú: 2004. Disponible en: http://www.oit. org.pe. 
OLESKER, Daniel. Crecimiento y exclusión. Nacimiento, consolidación y crisis del modelo de acumulación capitalista en Uruguay (1968-2000). Montevideo-Uruguay: Ed. Trilce, 2001.

ORGANIZACIÓN DE NACIONES UNIDAS PARA EL DESARROLLO INDUSTRIAL (ONUDI). International Year Book of Industrial Statistic. Viena: 2005.

ORGANIZACIÓN MUNDIAL DEL COMERCIO (OMC). Estadísticas del comercio mundial. Informes Anuales. Disponible en: http://www.omc.org.

PAOLILLO, Claudio. Con los días contados. Montevideo-Uruguay: Ed. Fin de Siglo, Colección Búsqueda. 2004.

PERRAUX, François. L'Europe Sans Rivage. In: BEAUD, Michel. Le systeme national mundial hierarchise. Paris-Francia: Editorial La Découverte, 1987.

PORTO, Luis. Para entender la crisis bancaria. Montevideo-Uruguay: Ed. Banda Oriental, 2002.

PRESIDENCIA DE LA REPÚBLICA. El gasto público en Uruguay. Oficina de Planeamiento y Presupuesto (OPP), oct. 2004.

PROGRAMA DE LAS NACIONES UNIDAS PARA EL DESARROLLO. PNUD. Desarrollo humano del Uruguay. Uruguay: 2005. Disponible en: http://www.undp.org.uy.

- La democracia en América Latina. Hacia una democracia de ciudadanos y ciudadanas. Buenos Aires- Argentina: Editorial Alfaguara, abr. 2004.

ROCCA, José. Crisis viejas de un nuevo milenio. Una mirada a la economía uruguaya. Montevideo-Uruguay: Ed. Nordam-Comunidad, 2002.

STOLOVICH, Luis. et al. Compra de carteras. Montevideo-Uruguay: Ed. Banda Orienta, 1986. 